\title{
Sistem Pengendali Pengambilan Gambar Pada Kamera DSLR Melalui Protokol PTP
}

\author{
Muhammad Iqbal $^{* 1}$, Triyogatama Wahyu Widodo ${ }^{2}$, Bakhtiar Aldino Ardi Sumbodo ${ }^{3}$ \\ ${ }^{1}$ Prodi Elektronika dan Instrumentasi, Jurusan Ilmu Komputer dan Elektronika, FMIPA UGM \\ ${ }^{2}$ Jurusan Ilmu Komputer dan Elektronika, FMIPA UGM, Yogyakarta \\ e-mail: *11muhammad.iqbal0512@gmail.com, 2yogatama@ugm.ac.id, \\ b.alldino.as@ugm.ac.id
}

\begin{abstract}
Abstrak
DSLR atau Digital Single Lens Reflex merupakan kamera professional yang menggunakan sensor digital berkualitas dengan ketajaman gambar yang tinggi. Kamera ini menggunakan berbagai macam lensa berdasarkan kebutuhan pemakai. Pengambilan gambar menggunakan kamera DSLR bukan perkara yang mudah, posisi dari objek serta intensitas cahaya mempengaruhi gambar yang dihasilkan. Pengaturan pada kamera DSLR ini bermacammacam sehingga seringkali menyulitkan penggunanya saat melakukan pengambilan gambar.

Pada penelitian ini dirancang bangun sebuah sistem yang dapat mengendalikan kamera DSLR untuk pengambilan gambar melalui protokol PTP. Pengambilan gambar ini diimplementasikan dengan menggunakan USB Host Shield, yaitu alat yang digunakan sebagai penghubung antara kamera DSLR dengan Arduino sebagai kontroler. Posisi dari kamera DSLR juga dapat diatur sesuai dengan pengaturan yang telah ditentukan menggunakan Servo dynamixel.

Hasil dari penelitian ini berupa sebuah alat yang mampu melakukan pengambilan gambar pada objek dengan mengirimkan instruksi melalui command yang ada pada serial monitor Arduino. Uji coba sistem dilakukan dengan pengujian pengambilan gambar melalui protokol PTP, perubahan posisi kamera, pengaruh sensitivitas kamera terhadap cahaya, serta pengaruh intensitas cahaya. Selain itu juga adanya kontras yang baik pada objek yang akan diambil gambarnya akan mempengaruhi proses auto focus, semakin rendah kontras dari objek yang akan diambil maka kamera semakin sulit mendapatkan fokus yang tepat.
\end{abstract}

Kata kunci-Kamera DSLR, Arduino, Servo dynamixel, USB Host Shield, Protokol PTP

\begin{abstract}
DSLR is a professional camera that uses a high-quality digital sensor with high image sharpness. This camera can use various lenses based on user needs. Taking pictures using a digital SLR camera is not an easy matter, the position of object, location, and intensity of light affect the resulting image.

In this research, designed and built a system that can control the DSLR cameras via PTP protocol. Image capture is implemented using the USB Host Shield, which is a tool that is used as a connector between a DSLR camera with an Arduino as a controller.

Results of this research is a tool that is capable of taking pictures on the object by sending instructions via existing command on the Arduino serial monitor. The system test is done by testing image capturing through the PTP protocol, the change of the camera position, the influence of the camera's sensitivity to light, as well as the influence of light intensity. The result is DSLR cameras via PTP protocol can take a picture, adjust the position, adjust the ISO in accordance with the needs of the object, and set the white balance according to the location where the image capturing done.
\end{abstract}

Keywords - DSLR Camera, Arduino, Servo Dynamixel, USB Host Shield, PTP Protocol

Received October 13 ${ }^{\text {th }}, 2016$; Revised October 20 ${ }^{\text {th }}, 2016$; Accepted October $27^{\text {th }}, 2016$ 


\section{PENDAHULUAN}

$\mathrm{F}$ tografi merupakan seni yang mempunyai banyak sekali peminat dari berbagai lapisan masyarakat. Dunia fotografi semakin berkembang dengan semakin banyaknya alat untuk merekam citra. Dimulai dari kamera yang menggunakan film sebagai alat penyimpan citra hingga yang menggunakan kartu memori sebagai alat penyimpan citra. Seiring dengan perkembangan jaman dan perkembangan kualitas hidup manusia, sekarang kamera DSLR (Digital Single Lens Reflect) pocket camera, dan semipro camera semakin menarik minat para pecinta fotografi.

Interkonektivitas kamera digital dengan perangkat lain merupakan salah satu perhatian utama konsumen dan produsen kamera digital. Fitur interkonektivitas dalam kamera digital memudahkan penggunanya untuk mengirim hasil gambar langsung dari kamera ke target yang diinginkan sesuai dengan aplikasi yang mendukung fitur tersebut. Saat ini berkembang standar baru dari fotografi untuk konektivitas fotografi digital yang dikenal sebagai Picture Transfer Protocol (PTP) [1].

Picture Transfer Protocol (PTP) merupakan protokol interkonektivitas perangkat fotografi digital yang bermaksud untuk mengganti dan menyatukan komunikasi antara perangkat pengolah gambar dan perangkat penerima lainnya, seperti PC [2]. Pemanfaatan protokol PTP akan lebih memudahkan pengguna kamera digital dalam pengambilan gambar beserta pengaturannya, selain itu juga jarak antara kamera dan objek yang akan diambil gambarnya dapat diatasi dengan pemanfaatan protokol ini. Pada dasarnya masih jarang penggunaan protokol PTP sebagai komunikasi dalam pengendalian pengambilan gambar.

Dilihat dari fitur yang disediakan oleh PTP maka pengguna kamera digital khususnya DSLR yang dilengkapi dengan protokol PTP akan dimudahkan dalam pengambilan gambar tanpa harus berada didekat kamera karena dengan memanfaatkan protokol PTP dapat dilakukan pengendalian pengambilan gambar [3]. Masalah lain yang mungkin muncul ketika seseorang ingin mengambil gambar dari suatu objek yaitu posisi dari kamera yang digunakan untuk mengambil gambar. Perubahan posisi kamera saat pengambilan gambar dapat mempengaruhi hasil yang diperoleh. Selain itu, keseimbangan saat pengambilan gambar menjadi hal penting agar tidak menimbulkan getaran yang juga dapat mempengaruhi hasil.

Dari permasalahan yang ada maka dibutuhkan suatu alat pengendalian pengambilan gambar pada kamera DSLR secara jarak jauh. Selain itu juga untuk meminimalisir getaran yang ditimbulkan dan menjaga keseimbangan saat pengambilan gambar, diimplementasikan sistem yang dapat mengendalikan posisi kamera DSLR dengan memanfaatkan gerak dari motor Servo.

\section{METODE PENELITIAN}

\subsection{Analisis Kebutuhan}

Sistem yang dirancang dalam penelitian ini merupakan suatu sistem dengan kemampuan pengendalian kamera DSLR yang digerakkan dengan dua buah servo. Pengendalian kamera tersebut dilakukan dengan menggunakan modul mikrokontroler yang akan dikomputasikan pada perangkat PC (personal computer). Secara keseluruhan diagram blok sistem ini dapat dilihat pada Gambar 1. Sistem dimulai ketika objek disorot oleh kamera DSLR, semua antarmuka berada pada PC (Personal Computer) sehingga pada saat PC memberikan command, Arduino akan memproses command tersebut, selanjutnya akan diakses oleh USB Host Controller sebagai komunikasi ke kamera Canon DSLR. Begitu pula pada kedua buah servo, pada saat PC (Personal Computer) memberikan command maka Arduino akan memproses dan mengirimkan paket data untuk menggerakkan Servo. 


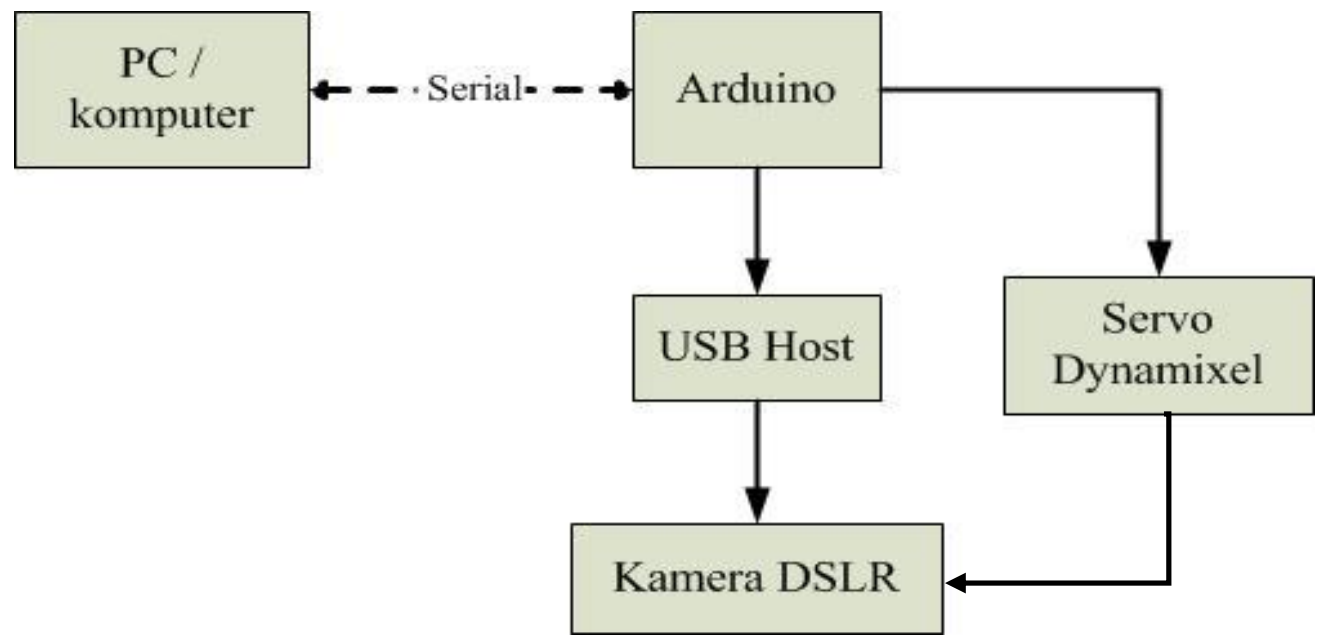

Gambar 1 Rancangan Perangkat Mekanis

\subsection{Rancangan Sistem}

Perancangan sistem merupakan rincian dari setiap tahapan yang dilakukan dalam sistem. Perancangan sistem digunakan untuk mengetahui alur kerja dari penelitian yang dilakukan. Pada penelitian ini, sistem yang akan dirancang terbagi menjadi tiga bagian yaitu rancangan sistem mekanik, rancangan sistem perangkat keras, dan rancangan sistem perangkat lunak.

\subsubsection{Rancangan Sistem Mekanik}

Perangkat mekanis yang digunakan pada sistem pengendalian kamera memiliki dua buah sudut kebebasan atau degree of freedom (DOF). Kedua buah DOF ini sebagai penggerak kamera untuk menggerakkan secara vertikal dan horizontal. Gerakan kamera secara horizontal dan vertikal digerakan oleh motor Servo dengan sudut 300 derajat. Putaran gerak Servo diberi batasan dengan posisi awal yang telah ditentukan. Rancangan ini akan di hubungkan dengan tripot, bentuk perancangan perangkat mekanis dapat dilihat pada Gambar 2.

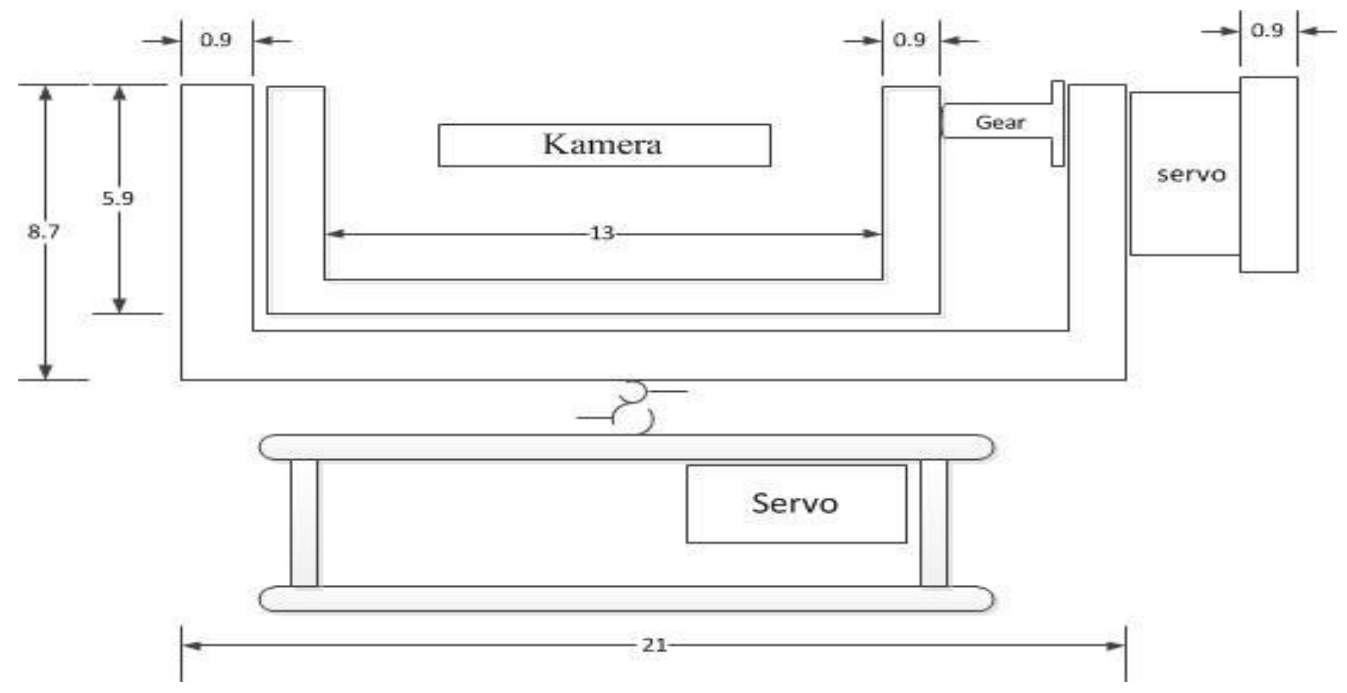

Gambar 1 Rancangan Perangkat Mekanis 


\subsubsection{Rancangan Sistem Perangkat Keras}

Sistem perangkat keras pada pengendalian kamera ini merupakan otak yang berupa mikrokontroler atau unit pemroses. Mikrokontroler yang digunakan pada sistem pengendalian kamera DSLR ini adalah Arduino Mega 2560. Mikrokontroler Arduino Mega 2560 mengumpulkan informasi dari perangkat USB modul untuk dapat berkomunikasi dengan kamera DSLR dan juga pengendalian terhadap pergerakan Servo.

Arduino Mega bertugas untuk mengendalikan dynamixel. Pengendalian dynamixel oleh Arduino Mega berdasarkan command yang di kirim oleh laptop. Command tersebut akan menggerakkan dynamixel, dengan memanfaatkan serial pada pin 14 di Arduino Mega sebagai TX. Pada sistem ini tidak menggunakan RX untuk itu dimanfaatkan pin ground yang terdapat pada Arduino Mega. Pengiriman instruksi diberikan untuk pengendalian pengambilan gambar pada kamera DSLR yang dihubungan dengan mikrokontroler Arduino Mega melalui USB Host shield. Arduino Mega akan mengendalikan gerak dynamixel agar kamera DSLR mampu menangkap gambar tepat pada objek yang diinginkan. Gambar 3 menunjukkan rancangan perangkat keras.

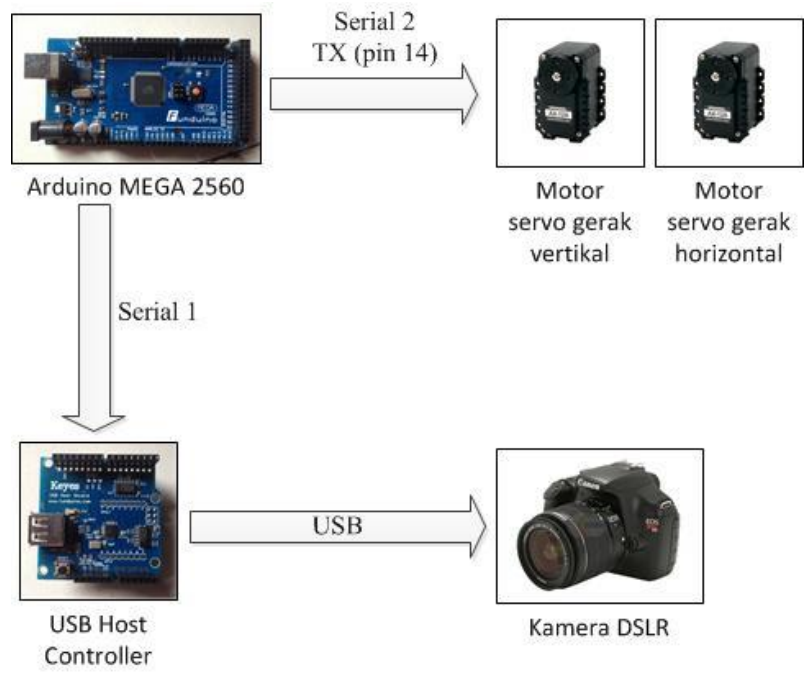

Gambar 3 Rancangan Perangkat Keras

\subsubsection{Rancangan Sistem Perangat Lunak}

Perancangan perangkat lunak meliputi analisis komunikasi serial antara laptop dengan Arduino serta protokol PTP yang digunakan. Tujuan dilakukan perancangan ini untuk memudahkan pada saat pengiriman command yang di kirim melalui laptop. Analisis komunikasi serial ini dilakukan melalui Arduino IDE yang telah tersedia sebagai compiler-nya. Perancangan perangkat lunak juga dilakukan untuk USB Host Controller melalui protocol PTP (Picture Transfer Protocol) agar mesinkronkan kamera DSLR dengan cara membaca perintah-perintah yang ada didalamnya.

Kamera DSLR Canon mendukung penggunaan perintah PTP standar untuk pengambilan gambar. Semua fungsi kamera, termasuk pengaturan fokus dan modus bidikan dikendalikan oleh firmware. Hal ini memungkinkan Arduino yang dilengkapi dengan USB Host Shield untuk mengambil kendali atas kamera sehingga sistem yang dibuat dapat melakukan pemotretan secara otomatis. Perintah-perintah yang diberikan berupa masukkan karakter hurufhuruf yang ada pada keyboard. Setiap karakter yang dimasukkan akan mewakili satu perintah pada perubahan setting di kamera. 


\subsection{Implementasi}

Kamera DSLR diimplementasikan sebagai alat pengambil gambar. Protokol yang ada didalamnya dimanfaatkan untuk pengambilan gambar secara otomatis dengan menggunakan PTP (Picture Transfer Protocol). Kamera DSLR yang digunakan dalam penelitian ini yaitu Canon EOS 1100D / Rebel T3i. Kamera ini dipilih sebagai perangkat pengambil gambar karena protokol pada device ini sudah cukup memenuhi kebutuhan dari tujuan penelitian ini.

Pada penelitian ini USB host controller MAX3421E diimplementasikan sebagai perangkat yang akan menjembatani komunikasi antara kontroler dengan kamera DSLR. Alasan pemilihan perangkat ini yaitu USB host controller MAX3421E sudah compatible dengan kontroler yang digunakan yaitu Arduino Mega 2560, selain itu juga beberapa perangkat Arduino sudah include dengan MAX3421E. Ada pula perangkat alternatif lain yang bisa digunakan sebagai USB host controller yaitu USB controller berbasis chip Vinculum VNC1A dari FTDI. Perangkat ini menggunakan komunikasi paralel first in first out (FIFO). Saat dilakukan implementasi menggunakan USB host controller FTDI penulis mengalami kesulitan dalam penggunaan perangkat tersebut untuk pengendalian kamera. Ada beberapa kemungkinan yang menjadi alasan mengapa USB host tersebut tidak bisa mengendalikan kamera, diantaranya yaitu board tersebut tidak bisa mengakses library yang digunakan untuk mengendalikan kamera, dalam hal ini penulis memanfaatkan library yang sudah ada sebelumnya. Implementasi kendali Servo ditunjukkan pada Gambar 4.

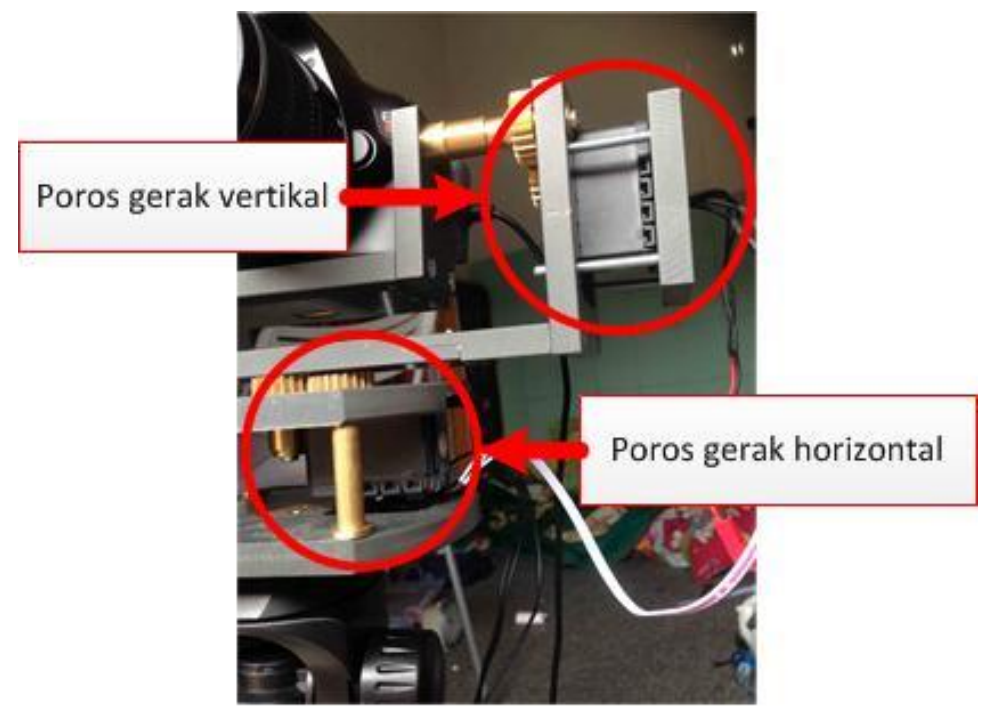

Gambar 4 Implementasi Kendali Servo

Implementasi mekanik yang digunakan pada penelitian ini, dilakukan dengan menyusun dua buah servo yang disusun agar mampu menopang dan mengarahkan kamera DSLR untuk berputar searah sumbu x (Pan), dan berputar searah sumbu y (Tilt). Masing - masing servo dapat berputar sejauh $180^{\circ}$, sehingga servo pertama (servo x) dapat memutar kamera untuk berputar dari posisi $0^{\circ}$ (menoleh ke kiri) sampai $180^{\circ}$ (menoleh ke kanan), dan posisi default adalah $90^{\circ}$ yaitu saat kamera menghadap kedepan. Untuk servo kedua (servo y) dapat memutar kamera untuk berputar dari posisi $0^{\circ}$ (menengadah ke atas) sampai $180^{\circ}$ (menunduk ke bawah), dan posisi default adalah $90^{\circ}$ yaitu saat kamera menghadap ke depan. Seluruh sistem mekanik ditopang oleh tripod agar mampu berdiri tegak dan dapat di atur ketinggian yang dikehendaki. Implementasi dari mekanik ditunjukan pada Gambar 5. 


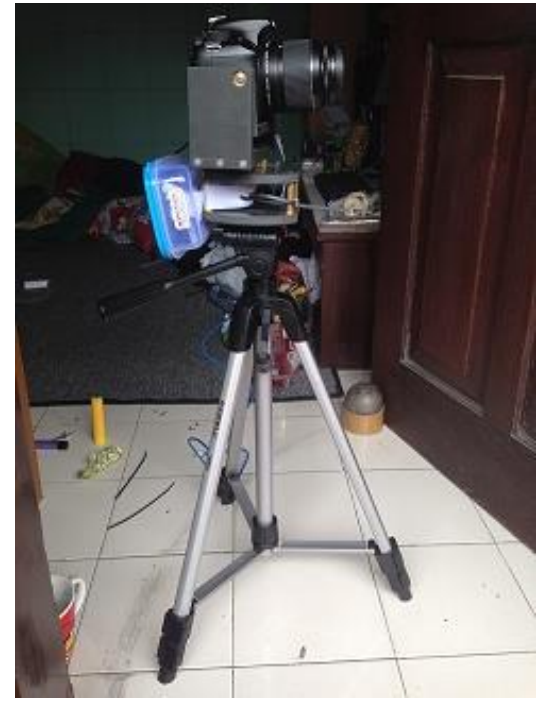

Gambar 5 Implementasi Mekanik

\section{HASIL DAN PEMBAHASAN}

\subsection{Pengujian Pengambilan Gambar}

Pengujian ini dilakukan untuk mengetahui apakah sistem sudah bisa mengendalikan kamera DSLR untuk mengambil gambar dari suatu objek. Cara yang digunakan untuk pengambilan gambar yaitu dengan memberikan instruksi dari laptop yang dikirimkan melalui komunikasi serial Arduino. Karakter yang dimasukkan untuk pengambilan gambar adalah angka satu "1". Sistem akan diletakkan pada posisi tertentu, ketika diberikan masukkan karakter angka satu "1" sistem akan melakukan pencarian titik fokus pada objek. Pencarian titik fokus ini menggunakan alamat 0x8003. Alamat tersebut sesuai dengan tipe kamera yang digunakan yaitu Canon EOS 1100D. Proses yang dilakukan selanjutnya sistem akan secara otomatis mengendalikan kamera untuk mengambil gambar dari objek. Hasil pengujian ini ditunjukan pada Gambar 6.

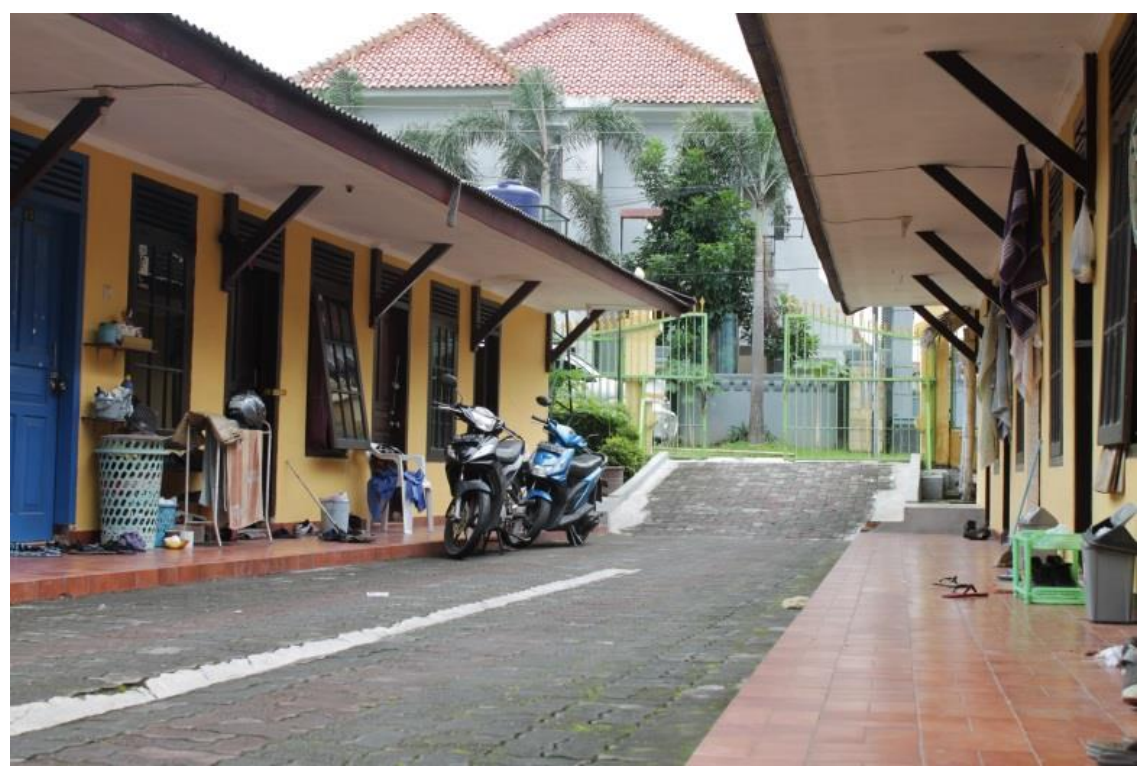

Gambar 6 Hasil Pengendalian Pengambilan Gambar

IJEIS Vol. 6, No. 2, October 2016: $117-128$ 
Hasil Gambar 6 menunjukkan bahwa pengendalian kamera DSLR melalui protokol PTP untuk mengambil gambar dari suatu objek telah berhasil dilakukan dengan memberikan instruksi masukan berupa karakter angka satu "1". PTP mendefinisikan beberapa konstruksi yang seluruhnya berada di dalam protokol tersebut, terutama pada koneksi logik antara inisiator dan responder. Gambar 7 merupakan format protokol PTP yang di kirimkan untuk melakukan pengaturan kamera.

\begin{tabular}{|l|l|l|l|}
\hline command packet & data packet & event packet & response packet \\
\hline
\end{tabular}

Gambar 7 Format Protokol PTP untuk Pengaturan Kamera

Urutan komunikasi protokol PTP dimulai dari salah satu perangkat mengeluarkan permintaan operasi. Operasi ini tergantung pada kode operasi yang di kirimkan, responden akan memberikan tanggapan dengan respon paket yang sesuai dengan permintaan. Jika respon memerlukan data lebih banyak dari pada yang bisa dimuat dalam respon paket (lebih dari 12 byte), maka paket data yang dihasilkan akan dikirim sebelum paket respon. Pemohon bertanggung jawab untuk mengetahui bagaimana menangani respon dan data paket yang tergantung pada perintah apa yang dikirim.

Protokol PTP tidak mengizinkan transaksi secara bersamaan, sehingga jika semua perintah, data, dan respon dilakukan secara bersamaan maka protokol PTP akan bekerja secara asinkron. Bagian yang cukup sulit dalam penelitian ini yaitu mengetahui bagaimana bentuk perintah, data, dan paket respon pada instruksi tertentu yang diinginkan, sementara protokol PTP mendefinisikan satu set standar perintah, tanggapan, dan properti.

\subsection{Pengujian Pengambilan Gambar dengan Variasi Posisi}

Posisi untuk mengambil gambar melalui kamera DSLR juga dapat diatur pada sistem ini. Cara pengendalian untuk menentukan posisi dari kamera menggunakan instruksi yang dikirimkan melalui serial monitor Arduino. Instruksi yang diberikan untuk mengatur posisi kamera yaitu berupa empat variasi posisi.

Masing-masing variasi posisi tersebut diwakili oleh karakter masukan yang berbeda pula. Posisi awal dari kamera dengan memberikan nilai pulsa 500. Nilai ini diambil sebagai nilai acuan atau nilai tengah pulsa dari total keseluruhan 1024. Nilai total pulsa 1024 dapat berputar sejauh 300 derajat. Perubahan posisi pada kamera, dilakukan dengan menambah dan mengurangi nilai pulsa acuan sesuai dengan pengaturan yang telah diberikan. Perubahanperubahan posisi tersebut dengan memberikan pulsa sebesar 10 (sepuluh) atau kurang lebih 3 derajat setiap melakukan variasi posisi.

Hasil pengujian yang dilakukan dengan pengendalian gerak Servo pada kamera DSLR menunjukkan bahwa Servo dapat melakukan variasi posisi sesuai parameter-parameter yang telah diberikan. Beberapa variasi perubahan posisi ini dilakukan secara maksimal. Kedua Servo yang digunakan untuk menggerakkan kamera DSLR dipasang pada mekanik yang telah dibuat khusus sehingga dapat menopang kamera sesuai berat dan ukurannya. Mekanik ini juga dibuat supaya bisa ditopang menggunakan tripod sehingga memudahkan penggunanya saat melakukan pengambilan gambar.

Akurasi dari pengaturan gerak motor Servo dilihat dari perbandingan nilai sudut yang dikirimkan dengan pembacaan busur untuk melihat perubahan gerak dari motor tersebut. Pengitungan akurasi perubahan gerak Servo ini dilakukan untuk mengetahui apakah besarnya gerakan servo yang dilakukan sudah sesuai dengan perintah yang dikirimkan. 
Tabel 1 Pengukuran Sudut Gerak Servo ke Arah Kanan

\begin{tabular}{|l|l|l|}
\hline No & $\begin{array}{l}\text { Sudut } \\
\text { Terkirim }\end{array}$ & $\begin{array}{l}\text { Sudut } \\
\text { Terbaca }\end{array}$ \\
\hline 1 & $2,92^{0}$ & $3^{0}$ \\
\hline 2 & $2,92^{0}$ & $5^{0}$ \\
\hline 3 & $2,92^{0}$ & $2,9^{0}$ \\
\hline 4 & $2,92^{0}$ & $3^{0}$ \\
\hline 5 & $2,92^{0}$ & $3^{0}$ \\
\hline 6 & $2,92^{0}$ & $3^{0}$ \\
\hline 7 & $2,92^{0}$ & $2,9^{0}$ \\
\hline 8 & $2,92^{0}$ & $2,9^{0}$ \\
\hline 9 & $2,92^{0}$ & $2,5^{0}$ \\
\hline Jumlah & $26,28^{0}$ & $28,2^{0}$ \\
\hline \multicolumn{2}{|l|}{ Rata - rata akurasi } & $92,69 \%$ \\
\hline
\end{tabular}

Tabel 2 Pengukuran Sudut Gerak Servo ke Arah Atas

\begin{tabular}{|l|l|l|}
\hline No & $\begin{array}{l}\text { Sudut } \\
\text { Terkirim }\end{array}$ & $\begin{array}{l}\text { Sudut } \\
\text { Terbaca }\end{array}$ \\
\hline 1 & $2,92^{0}$ & $4^{0}$ \\
\hline 2 & $2,92^{0}$ & $3^{0}$ \\
\hline 3 & $2,92^{0}$ & $3^{0}$ \\
\hline 4 & $2,92^{0}$ & $3^{0}$ \\
\hline 5 & $2,92^{0}$ & $4^{0}$ \\
\hline 6 & $2,92^{0}$ & $3^{0}$ \\
\hline 7 & $2,92^{0}$ & $3^{0}$ \\
\hline 8 & $2,92^{0}$ & $3,1^{0}$ \\
\hline 9 & $2,92^{0}$ & $2,9^{0}$ \\
\hline Jumlah & $26,28^{0}$ & $29^{0}$ \\
\hline \multicolumn{2}{|l|}{ Rata - rata akurasi } & $89,65 \%$ \\
\hline
\end{tabular}

Tabel 3 Pengukuran Sudut Gerak Servo ke Arah Kiri

\begin{tabular}{|l|l|l|}
\hline No & $\begin{array}{l}\text { Sudut } \\
\text { Terkirim }\end{array}$ & $\begin{array}{l}\text { Sudut } \\
\text { Terbaca }\end{array}$ \\
\hline 1 & $2,92^{0}$ & $3^{0}$ \\
\hline 2 & $2,92^{0}$ & $2,9^{0}$ \\
\hline 3 & $2,92^{0}$ & $3^{0}$ \\
\hline 4 & $2,92^{0}$ & $4^{0}$ \\
\hline 5 & $2,92^{0}$ & $4^{0}$ \\
\hline 6 & $2,92^{0}$ & $3^{0}$ \\
\hline 7 & $2,92^{0}$ & $3^{0}$ \\
\hline 8 & $2,92^{0}$ & $2,9^{0}$ \\
\hline 9 & $2,92^{0}$ & $3,1^{0}$ \\
\hline Jumlah & $26,28^{0}$ & $28,9^{0}$ \\
\hline Rata - rata akurasi & $90,03 \%$ \\
\hline
\end{tabular}


Tabel 4 Pengukuran Sudut Gerak Servo ke Arah Bawah

\begin{tabular}{|l|l|l|}
\hline No & $\begin{array}{l}\text { Sudut } \\
\text { Terkirim }\end{array}$ & $\begin{array}{l}\text { Sudut } \\
\text { Terbaca }\end{array}$ \\
\hline 1 & $2,92^{0}$ & $3^{0}$ \\
\hline 2 & $2,92^{0}$ & $4^{0}$ \\
\hline 3 & $2,92^{0}$ & $3^{0}$ \\
\hline 4 & $2,92^{0}$ & $2,9^{0}$ \\
\hline 5 & $2,92^{0}$ & $3,1^{0}$ \\
\hline 6 & $2,92^{0}$ & $3^{0}$ \\
\hline 7 & $2,92^{0}$ & $2,9^{0}$ \\
\hline 8 & $2,92^{0}$ & $3^{0}$ \\
\hline 9 & $2,92^{0}$ & $2,9^{0}$ \\
\hline Jumlah & $26,28^{0}$ & $27,8^{0}$ \\
\hline Rata - rata akurasi & $94,23 \%$ \\
\hline
\end{tabular}

Tabel 1, Tabel 2, Tabel 3, dan Tabel 4 menunjukkan hasil pengukuran sudut gerak servo ke arah kanan, atas, kiri, dan bawah. Sudut terkirim merupakan besarnya nilai sudut yang terkirim (set point), sedangakan sudut terbaca merupakan hasil pembacaan gerak motor Servo dilihat dari busur. Busur digunakan sebagai alat ukur perubahan gerak Servo untuk melihat nilai akurasinya, apakah sudut terbaca sudah sesuai dengan nilai sudut yang di kirimkan.

Nilai akurasi rata - rata dari setiap perubahan gerak motor Servo diatas $90 \%$ atau bisa dikatakan kesalahan yang terjadi masih dalam toleransi yaitu tidak lebih dari $10 \%$. Kesalahan yang terjadi dimungkinkan karena adanya gesekkan pada geer yang digunakan untuk menopang papan kamera dengan papan penyangganya, sehingga membuat gerak Servo menjadi tidak maksimal sesuai dengan nilai sudut yang diberikan.

\subsection{Sensitifitas Kamera Terhadap Cahaya}

Fotografi dibangun dari tiga komponen exposure, yaitu: Aperture, Shutter Speed dan Sensitifitas / ISO. ISO adalah ukuran tingkat sensifitas sensor kamera terhadap cahaya. Semakin tinggi pengaturan ISO maka semakin sensitif sensor terhadap cahaya. Dalam pengujian ini dilakukan pengaturan ISO yang berbeda-beda pada objek yang sama. Objek yang akan diambil gambarnya, pengaturan white balance dalam keadaan Auto. Variasi pengaturan ISO yang diberikan bertujuan untuk melihat hasil pengambilan gambar oleh kamera DSLR menggunakan instruksi masukkan yang diberikan melalui laptop. Hasil pengambilan gambar pada saat pengaturan ISO terdapat pada lampiran 2 hasil penelitian.

Proses pengaturan ISO yang dilakukan pada sistem ini juga memanfaatkan alamat yang ada pada library dari kamera tersebut. Masing - masing pengaturan ISO memiliki alamatnya sendiri - sendiri, jika dalam sistem digunakan delapan pengaturan ISO, berarti ada delapan alamat berbeda yang disisipkan untuk pengaturan ISO. Sebagi contoh alamat 0x00 yang ada pada library canoneos.h digunakan sebagai pengaturan ISO auto. Lain halnya dengan alamat 0x50 digunakan sebagai pengaturan ISO 200.

ISO ditunjukkan dengan angka. Semakin besar angkanya, semakin besar sensitifitasnya terhadap cahaya. Sensitifitas ini adalah kemampuan menyerap cahaya, sehingga pada kondisi dan pengaturan pemotretan yang sama, foto dengan ISO 200 dan ISO 800, hasilnya akan jauh lebih terang yang menggunakan ISO 800. Namun, pengaturan ISO yang tinggi memiliki dampak pada hasilnya. Semakin sensitif sensor terhadap cahaya, maka bintik piksel dalam foto semakin jelas terlihat. Bintik piksel yang jelas itu sering disebut noise atau grain. Foto jadi terlihat berpasir, karena semakin tinggi ISO, noise-nya juga akan semakin tinggi. Tabel 5 menunjukkan hasil pengambilan gambar dengan pengaturan ISO. 
Tabel 5 Hasil Pengendalian Pengambilan Gambar dengan Pengaturan ISO

\begin{tabular}{|c|c|c|}
\hline $\begin{array}{c}\text { Karakter } \\
\text { Masukkan }\end{array}$ & Pengaturan ISO & Hasil Pengambilan Gambar \\
\hline & & \\
$\mathrm{E}$ & Auto & \\
& & \\
\hline
\end{tabular}

\subsection{Pengaruh Intensitas Cahaya}

Intensitas cahaya memiliki pengaruh yang cukup besar terhadap pengambilan gambar. Besar kecilnya intesitas cahaya akan mempengaruhi kinerja dari kamera sebagai alat yang digunakan untuk mengambil gambar. Ketika objek tertentu dikenakan intensitas cahaya yang besar, maka kamera akan menangkap objek yang memiliki warna yang lebih terang. Sedangkan jika intensitas cahaya yang kecil, maka kamera akan menangkap objek yang memiliki warna yang terlalu gelap. Pengaruh intensitas cahaya akan mempengaruhi dari hasil pengambilan gambar oleh kamera DSLR.

Proses pengaturan white balance yang dilakukan dalam penelitian ini dengan memasukkan karakter yang telah diatur sebelumnya maka secara otomatis pengaturan white balance yang ada pada kamera DSLR akan berubah. Proses pengaturan white balance dengan cara mengambil fungsi yang ada di dalam library canoneos.h. Di dalam library yang akan diakses sudah terdapat bermacam - macam kode yang bisa dimanfaatkan sesuai dengan kebutuhan penggunanya. Dalam penelitian ini digunakan Eos.SetProperty(EOS_DPC_WhiteBalance, 1) sebagai pengaturan white balance. Ketika nilai 1 (satu) yang dipilih maka white balance akan berubah menjadi Day light. Nilai dari listing program tersebut yang membedakan pengaturan white balance satu sama lain.

Pengujian dilakukan dengan memvariasikan pengaturan white balance. Pada saat pengujian, kamera diletakkan pada lokasi yang telah ditentukan sebelumnya sesuai dengan kebutuhan pengujian. Perbedaan hasil gambar dengan pengaturan white balance dapat dilihat pada Tabel 6 . 
Tabel 6 Hasil Pengendalian Pengambilan Gambar dengan Pengaturan WB

\begin{tabular}{|c|c|c|}
\hline $\begin{array}{c}\text { Karakter } \\
\text { Masukkan }\end{array}$ & $\begin{array}{c}\text { Pengaturan White } \\
\text { Balance }\end{array}$ & Hasil Pengambilan Gambar \\
\hline F & Auto & \\
\hline G & & \\
\hline
\end{tabular}

\section{KESIMPULAN}

Dari hasil pengamatan, pengujian, dan analisis pada hasil yang diperoleh, kesimpulan sebagai berikut.

1. Pengambilan gambar pada kamera dapat di kendalikan tanpa harus menggunakan shutter yang disediakan pada kamera DSLR tetapi dengan memanfaatkan protokol PTP yang ada di dalamnya.

2. Komunikasi yang dilakukan antara PC dengan kamera memanfaatkan Arduino sebagai proxy, dimana Arduino akan meneruskan permintaan yang di kirim oleh PC dan mengakses library PTP untuk mengendalikan kamera yang terhubung dengan USB host.

3. Perubahan gerak posisi yang dilakukan pada kamera DSLR untuk arah kanan dan kiri maksimal sebesar $120^{\circ}$ serta arah atas dan bawah maksimal $30^{\circ}$.

4. Nilai akurasi rata - rata dari motor Servo dynamixel dalam pengaturan gerak kamera DSLR ke arah kanan sebesar $92,69 \%$, atas $89,65 \%$, kiri 90,03\%, dan bawah $94,23 \%$

\section{SARAN}

Berikut saran-saran yang dapat dilakukan untuk pengembangan dalam penelitian selanjutnya yang sejenis :

1. Pengendalian pengambilan gambar dapat dilakukan dari sistem secara wireless ke komputer atau laptop sehingga tidak perlu menggunakan kabel serial sebagai komunikasi data.

2. Pemanfaatan protokol PTP tidak hanya terbatas pada pengendalian pengambilan gambar tetapi juga bisa dikembangkan untuk mengirimkan hasil gambar yang diperoleh ke komputer atau laptop. 


\section{UCAPAN TERIMA KASIH}

Penulis mengucapkan terima kasih kepada semua pihak yang telah memberi dukungan baik secara moril maupun materiil terhadap penelitian ini.

\section{DAFTAR PUSTAKA}

[1] Bigioi, P., Corcoran, P., \& Susanu, G. (2002). Digital Imaging Using PTP (Picture Transfer Protocol), 54-55.

[2] Bigioi, P., Steinberg, E., Susanu, G., \& Corcoran, P. (2005). PTP/IP- Transport Layer for Picture Transfer Protocol, 25-26.

[3] Bigioi, P., Susanu, G., Corcoran, P., \& Mocanu, I. (2002). Digital camera connectivity solutions using the picture transfer protocol (PTP). IEEE Transactions on Consumer Electronics, 48(3), 417-427. doi:10.1109/TCE.2002.1037023 